\title{
Endocannabinoid-Specific Impairment in Synaptic Plasticity in Striatum of Huntington's Disease Mouse Model
}

\author{
๑Darja D. Sepers, ${ }^{1}$ Amy Smith-Dijak, ${ }^{1,2}$ Jeff LeDue, ${ }^{1}$ Karolina Kolodziejczyk, ${ }^{1}{ }^{\circledR K e n}$ Mackie, ${ }^{3}$ and ${ }^{\circ}$ Lynn A. Raymond ${ }^{1}$ \\ ${ }^{1}$ Department of Psychiatry and Djavad Mowafaghian Centre for Brain Health, ${ }^{2}$ Graduate Program in Neuroscience, University of British Columbia, \\ Vancouver, British Columbia V6T1Z3, Canada, and 32Department of Psychological and Brain Sciences, Indiana University, Bloomington, Indiana 47405-7007
}

\begin{abstract}
Huntington's disease (HD) is an inherited neurodegenerative disease affecting predominantly striatum and cortex that results in motor and cognitive disorders. Before a motor phenotype, animal models of HD show aberrant cortical-striatal glutamate signaling. Here, we tested synaptic plasticity of cortical excitatory synapses onto striatal spiny projection neurons (SPNs) early in the YAC128 mouse model of HD. High-frequency stimulation-induced long-term depression, mediated by the endocannabinoid anandamide and cannabinoid receptor 1 (CB1), was significantly attenuated in male and female YAC128 SPNs. Indirect pathway SPNs, which are more vulnerable in HD, were most affected. Our experiments show metabotropic glutamate receptor and endocannabinoid 2-arachidonoylglycerol-dependent plasticity, as well as direct CB1 activation by agonists, was similar in YAC128 and FVB/N wild-type SPNs suggesting that presynaptic CB1 is functioning normally. These results are consistent with a specific impairment in postsynaptic anandamide synthesis in YAC128 SPN. Strikingly, although suppression of degradation of anandamide was not effective, elevating 2-arachidonoylglycerol levels restored long-term depression in YAC128 striatal neurons. Together, these results have potential implications for neuroprotection and ameliorating early cognitive and motor deficits in HD.
\end{abstract}

Key words: endocannabinoid; Huntington disease; striatum

\section{Significance Statement}

Huntington's disease (HD) is an inherited neurodegenerative disease with no cure. Recent studies find impairment of the endocannabinoid system in animal models but the functional implication for synaptic plasticity in HD remains unclear. Sepers et al. show a selective deficit in synaptic plasticity mediated by the endocannabinoid anandamide, but not 2-arachidonoylglycerol in a mouse model of HD. The deficit is rescued by selectively elevating levels of 2-arachidonoylglycerol produced on-demand. This mechanism could be targeted in the development of future therapeutics for HD.

\section{Introduction}

Huntington's disease (HD) is a neurodegenerative disorder caused by a CAG expansion mutation in the gene that encodes huntingtin protein $(\mathrm{mHtt})$. A striking feature of $\mathrm{HD}$ pathology is the loss of neurons in the striatum. Greater than $90 \%$ of striatal neurons are GABAergic spiny projection neurons (SPNs) of two main

Received June 21, 2017; revised 0ct. 27, 2017; accepted Nov. 12, 2017.

Author contributions: M.D.S., J.L., and L.A.R. designed research; M.D.S., A.S.-D., and K.K. performed research; K.M. contributed unpublished reagents/analytic tools; M.D.S., A.S.-D., J.L., and K.K. analyzed data; M.D.S., A.S.-D., J.L., K.K., K.M., and L.A.R. wrote the paper.

This work was supported by grants from the Cure Huntington's Disease Initiative Foundation, the Canadian Institutes of Health Research (FDN-143210), and the U.S. National Institutes of Health (DA011322 and DA021696). We thank Lily Zhang and Rujun Kang for technical assistance, Dr. Mathieu Vanni and Pumin Wang for assistance with stereotaxic injections, and Dr. Vahri Beaumont for many helpful discussions of the data. We thank Dr. Amber Southwell and Dr. Michael Hayden, Centre for Molecular Medicine and Therapeutics, University of British Columbia, for providing the Q175FDN mice used in this study. Additional funding support for this study was provided by the Huntington Society of Canada.

The authors declare no competing financial interests.

Correspondence should be addressed to Dr. Lynn A. Raymond, Department of Psychiatry, Djavad Mowafaghian Centre for Brain Health, University of British Columbia, 2255 Wesbrook Mall, Vancouver, BC V6T 1Z3, Canada. E-mail: lynn.raymond@ubc.ca.

https://doi.org/10.1523/JNEUROSCl.1739-17.2017

Copyright $\odot 2018$ the authors $\quad 0270-6474 / 18 / 380544-11 \$ 15.00 / 0$ subtypes: those expressing predominantly D1-type dopamine receptors that project to the direct pathway [D1-SPNs (dSPNs)] involved in facilitating movement, and those expressing mainly D2-type dopamine receptors that form the indirect pathway [D2SPNs (iSPNs)] involved in suppressing movement. Although $>90 \%$ of both types of SPNs are lost by late-stage HD, D2-SPNs are more vulnerable and affected earlier (Plotkin and Surmeier, 2015; Reiner et al., 1988).

Excitatory input to the striatum comes from all areas of the cortex and the thalamus. A long held hypothesis is that excitotoxicity contributes to vulnerability of striatal SPNs in HD, due in part to increased release of cortical glutamate (André et al., 2011a) onto SPNs that show enhanced expression of extrasynaptic NMDAR (Milnerwood et al., 2010), thereby leading to reduced cell survival signaling (Hardingham and Bading, 2010; Dau et al., 2014; Gladding et al., 2014). In normal brain function, SPNs control firing rates by postsynaptically-induced feedback to presynaptic terminals to downregulate glutamate release. This long-term decrease in synaptic efficacy [long-term depression (LTD)] at corticostriatal synapses is involved in motor skill, instrumental and response learning (Lovinger, 2010). 
A

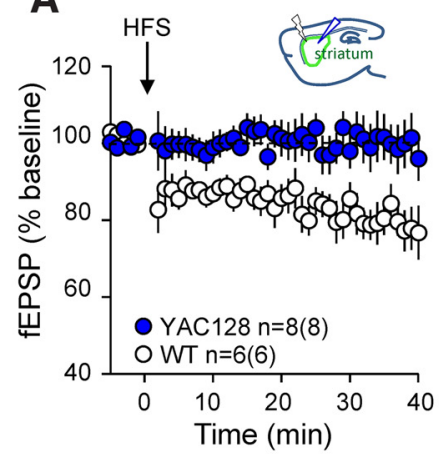

D

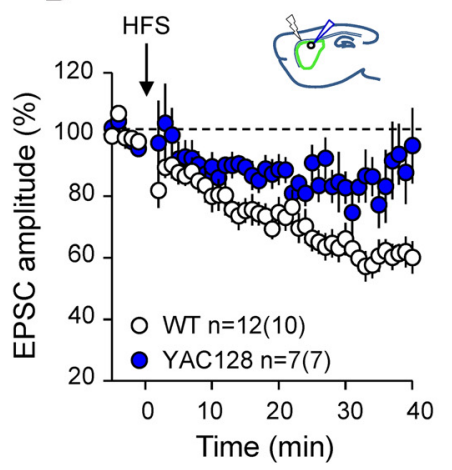

G

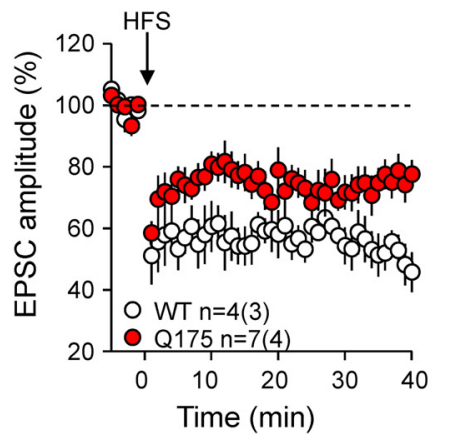

B

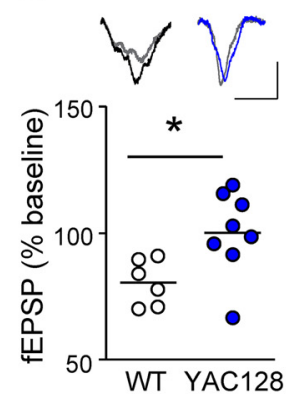

E
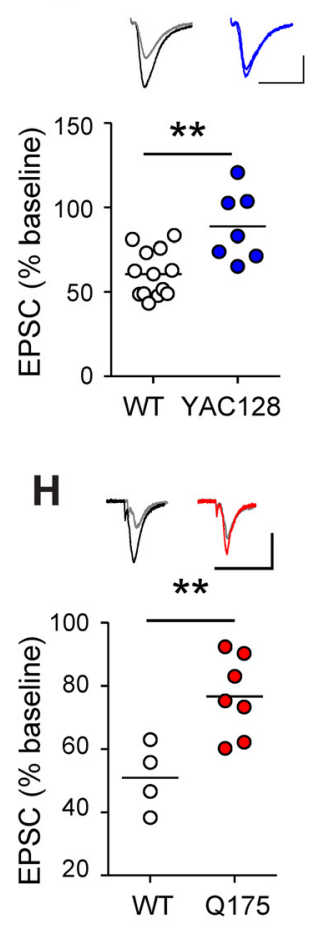

C
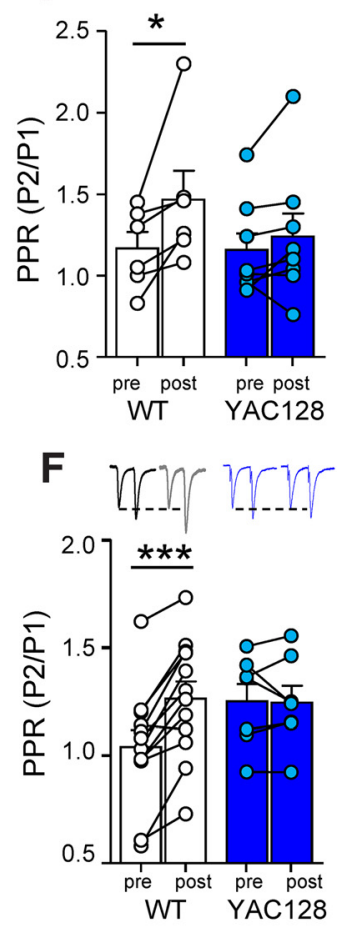

I

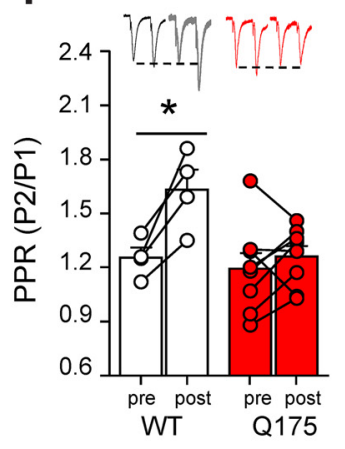

ylglycerol (2-AG), and $N$-arachidonoyl-ethanolamine (anandamide), which activate presynaptic cannabinoid receptor 1 (CB1) to reduce glutamate release from cortical terminals (Ronesi et al., 2004; Lovinger, 2010). There is an early reduction in CB1 expression in the striatum of HD patients and animal models (Glass et al., 2000; Dowie et al., 2009; Blázquez et al., 2011). Recent studies also show that lack of CB1 exacerbates the motor phenotype and neuropathology in animal models of HD (Blázquez et al., 2011; Mievis et al., 2011). The production of eCB could reduce glutamate release in the striatum in HD and thereby mitigate the deleterious effects of excess glutamate signaling. Whether this capacity is fully realized in $\mathrm{HD}$ is unknown.

Impaired hippocampal synaptic plasticity has been documented in HD mouse models. Less is known about the impact of the HD mutation on synaptic plasticity at corticostriatal synapses, which show early changes in basal synaptic transmission in several HD mouse models. Dopamine D2 receptors are downregulated in early HD in iSPNs that project to the globus pallidus (Glass et al., 2000). In contrast, D1 receptor activation on dSPNs and dopamine tone is elevated at this stage (André et al., 2011a,b), consistent with the early emergence of uncontrollable movements called chorea in humans with HD. The normal ability of the D2 receptor on iSPNs to upregulate eCB synthesis may also be impaired in HD and contribute to the imbalance of the two pathways. In the present study, we investigate long and short-term synaptic plasticity mediated by eCB in the YAC128 model of HD.

Figure 1. LTD in dorsal striatum is impaired in YAC128 mice. A, Averaged time course of fEPSP amplitude recorded in the dorsal striatum before and after high-frequency cortical afferent stimulation at time 0 ( 4 trains at $100 \mathrm{~Hz}$ for $1 \mathrm{~s}$ separated by $10 \mathrm{~s}$ ) in FVB (WT) and YAC128 Huntington mice. Circles represent the average of four fEPSP at $0.06 \mathrm{~Hz}$ normalized to baseline then presented as mean and S.E.M. for each group. Inset, Sagittal slice orientation with field recording electrode in blue and stimulating electrode in black. $B$, Summary showing normalized fEPSP amplitude 30-35 min post-HFS for each experiment is significantly lower in WT than in YAC128 striatum. ${ }^{*} p=0.0238$ Representative traces above show WT baseline fEPSP (black), post-HFS (gray), and YAC128 baseline (blue) overlapped with post-HFS (gray). Scale bar, $0.2 \mathrm{mV}, 5 \mathrm{~ms}$. C, PPR pre-HFS and $30 \mathrm{~min}$ post-HFS is increased in WT, ${ }^{*} p=0.0292$ but not YAC128 dorsal striatum. D. Time course summary showing evoked whole-cell EPSC $s$ in randomly selected WT and YAC128 SPNs normalized to baseline with LTD induction at time 0 by HFS (arrow; 4 trains at $100 \mathrm{~Hz}$ for $1 \mathrm{~s}$ paired with depolarization to $0 \mathrm{mV}$ separated by $10 \mathrm{~s}$ ). Inset, Sagittal slice with whole-cell recording in the dorsal striatum and stimulating in the corpus callosum. $\boldsymbol{E}$, Mean responses $35-40$ min after HFS in WT are significantly different from YAC128. ${ }^{* *} p=0.0033$ Representative traces of WT (left) and YAC128 (right). Scale bar, 100 pA, 50 ms. F, PPR of EPSCs is increased in WT but not YAC128 SPNs after HFS. ${ }^{* *} p=0.0001$ In representative traces the first response is scaled to show the change in ratio after HFS. G, Time course summary showing normalized EPSCs in randomly selected SPNs from WT and Q175 Huntington mice. $\boldsymbol{H}$, Responses $35-40$ min after HFS in WT are significantly different from Q175 with representative traces in WT (black) and Q175 (red). ${ }^{* *} p=0.0079$ I, PPR of EPSCs is increased after HFS in WT but not Q175. ${ }^{*} p=0.0172$.

Induction of LTD by high-frequency stimulation of cortical afferents requires activation of postsynaptic Group I mGluRs and L-type voltage-gated calcium channels (Cav1.3, activated upon depolarization above $-60 \mathrm{mV}$; Gerdeman et al., 2002; Ronesi et al., 2004; Kreitzer and Malenka, 2005; Lovinger, 2010). Elevated intracellular $\mathrm{Ca}^{2+}$ and phospholipase activation stimulate synthesis and release of endocannabinoids (eCB), 2-arachidono-

\section{Materials and Methods}

All procedures were performed in accordance with the Canadian Council on Animal Care and University of British Columbia Animal Care Committee regulations. Experiments were conducted in male and female transgenic YAC128 mice (Slow et al., 2003), expressing full-length human huntingtin with 128 CAG repeats on a yeast-artificial chromosome, and the genetic background strain $\mathrm{FVB} / \mathrm{N}$ [wild-type (WT)] at 1-2 months of age (unless otherwise indicated) and the Q175FDN model of HD (Southwell et al., 2016). In experiments with identified SPNs, YAC128 mice were crossbred to drd2-eGFP BAC transgenic mice on an FVB/NJ background obtained from the Surmeier laboratory at Northwestern University (Heintz, 2004). Initial experiments were conducted in homozygous line 55 YAC128 (Figs. 1 and $6 A, B, E)$, which shows less mutant huntingtin expression than heterozygous line 53 mice (Graham et al., 2009); the latter cannot be bred to homozygosity. Although we also used line 55 YAC128 in initial experiments in which we isolated iSPN by crossing with D2-eGFP mice (see Fig. $4 A-C, E, F)$, we switched to the YAC128 line 53 for further experiments 
(Figs. 2, 3, 5-7) so that mutant huntingtin expression in the offspring of this cross would be maintained at the same levels as the original YAC128(53) line.

\section{Slice preparation}

Animals were deeply anesthetized with isofluorane vapor, decapitated, and the brain rapidly removed. Acute sagittal brain slices $(300 \mu \mathrm{m})$ containing the dorsolateral striatum were cut on a vibratome (Leica VT1000) in ice-cold artificial CSF (aCSF; with $0.5 \mathrm{~mm} \mathrm{CaCl}_{2}$ and 2.5 $\mathrm{mM} \mathrm{MgCl}_{2}$ ) equilibrated with $95 \% \quad \mathrm{O}_{2} / 5 \%$ $\mathrm{CO}_{2}$. Slices were transferred to a holding chamber with aCSF at $37^{\circ} \mathrm{C}$ containing the following (in $\mathrm{mm}$ ): $125 \mathrm{NaCl}, 2.5 \mathrm{KCl}, 25$ $\mathrm{NaHCO}_{3}, 1.25 \mathrm{NaH}_{2} \mathrm{PO}_{4}, 1 \mathrm{MgCl}_{2}, 2 \mathrm{CaCl}_{2}, 10$ glucose, $\mathrm{pH} 7.3-7.4,305-310 \mathrm{mosmol} / \mathrm{L}^{-1}$ for $45 \mathrm{~min}$ then maintained at room temperature for a minimum of $1 \mathrm{~h}$ for whole-cell experiments and $3 \mathrm{~h}$ for field potential experiments before recording. In the recording chamber, slices were equilibrated for $20 \mathrm{~min}$ while being continuously superfused at room temperature with oxygenated aCSF at $1-2 \mathrm{ml} / \mathrm{min}$ containing picrotoxin (50 $\mu \mathrm{M}$; Tocris Bioscience) to block $\mathrm{GABA}_{\mathrm{A}}$ receptor-mediated inhibitory responses.

\section{Chemicals}

All drugs were obtained from Tocris Bioscience. (2S)-2-Amino-2-[(1S, 2S)-2-carboxycycloprop-1yl]-3-(xanth-9-yl) propanoic acid disodium salt (LY341495) was dissolved in water. Picrotoxin was dissolved directly in aCSF. $\mathrm{N}$-( piperidin-1-yl)-5-(4-iodophenyl)-1-(2,4-dichlorophenyl)-4-methyl-1H-pyrazole-3carboxamide (AM251), (R)-(+)-[2, 3-dihydro-5-methyl-3-(4-morpholinylmethyl)pyrrolo[1,2,3-de]-1, 4-benzoxazin-6-yl]-1-naphthalenylmethanone mesylate (WIN55,212-2), (-)-cis-3-[2-hydroxy-4-(1,1-dimethylheptyl)phenyl]-trans-4-(3-hydroxypropyl)cyclohexanol (CP55,940), 4-[bis(1,3-benzodioxol-5-yl)hydroxymethyl]-1-piperidinecarboxylic acid 4-nitrophenyl ester (JZL184), (RS)-3,5-Dihydroxyphenylglycine (DHPG), and cyclohexylcarbamic acid 3'-(aminocarbonyl)-[1,1'-biphenyl]-3-yl ester (URB597) were dissolved in DMSO. The concentration of DMSO in aCSF never exceeded $0.1 \%$. Selected experiments with AM251, CP55,940, and WIN55,212-2 included $0.5 \mathrm{~g} / \mathrm{L}$ bovine serum albumin (BSA) as a carrier (Sheinin et al., 2008).

\section{Extracellular recordings}

Data were acquired with a Multiclamp700 or Axopatch 200A amplifier and Clampfit 10 software (Molecular Devices), digitized at $100 \mathrm{kHz}$ and filtered at $20 \mathrm{kHz}$ for extracellular field EPSPs. Test stimuli were delivered every $15 \mathrm{~s}$ by a glass micropipette electrode filled with aCSF and placed $\sim 150 \mu \mathrm{m}$ dorsal to the site of recording to evoke a robust submaximal response (80-300 $\mu \mathrm{A}$ for $100-150 \mu$ s duration). The high-frequency stimulation protocol consisted of four $100 \mathrm{~Hz}$ trains of $1 \mathrm{~s}$ duration with an interval of $10 \mathrm{~s}$. Stimuli were at the same intensity used for the test pulses. fEPSP amplitude was averaged over the $5 \mathrm{~min}$ baseline and compared with the averaged fEPSP amplitude 30-35 min poststimulus train. Experiments with agonists CP55,940 and WIN55,212-2 include BSA in the aCSF.

\section{Whole-cell voltage-clamp}

Induction of long-term depression. Pipettes (3-5 M $\Omega$ ) were made from borosilicate glass capillaries on a Narishige micropipette puller (Narishige International). The intracellular solution was Cs-based as follows (mM): 120 cesium methane-sulfonate $\left(\mathrm{CH}_{3} \mathrm{O}_{3} \mathrm{SCs}\right), 5 \mathrm{CsCl}, 4 \mathrm{NaCl}$, $1 \mathrm{MgCl}_{2}$, 5 EGTA, 5 MgATP, 0.5 MgGTP, 5 QX-314 Cl, 10 tetraethylammonium chloride, and 10 HEPES, pH 7.25, osmolarity 290 mOsm. Whole-cell patch-clamp recording was performed with an Axopatch$200 \mathrm{~A}$ amplifier and pClamp 10 software digitized at $20 \mathrm{kHz}$ and filtered at $5 \mathrm{kHz}$. To evoke synaptic currents, two test stimuli (100 $\mu$ s duration) 50 ms apart were delivered every $15 \mathrm{~s}$ with a glass electrode (2-3 M $\Omega$ ) filled with aCSF and placed in the white matter dorsal to the striatum. Pairedpulse ratios (PPRs) were calculated by dividing the amplitude of the second pulse by the amplitude of the first. Unless otherwise indicated SPNs were maintained voltage-clamped at $-70 \mathrm{mV}$ during all experiments. The conditioning stimulus to evoke LTD was four episodes of high-frequency stimulation (HFS; $100 \mathrm{~Hz}$ ) for $1 \mathrm{~s}$ paired with depolarization to $0 \mathrm{mV}$ with a $10 \mathrm{~s}$ interval between episodes. To evaluate the access resistance $(\mathrm{Ra})$, a $10 \mathrm{mV}$ hyperpolarizing pulse was applied before each pair of evoked EPSCs. The experiments in which Ra changed $>20 \%$ were rejected. If linear regression of EPSC amplitudes over the baseline period showed a non-zero slope the experiment was rejected. Initially SPNs were randomly selected for recording from brain slices of WT and YAC128 mice at 1-2 months of age. To differentiate the two major types of SPNs, experiments were done in $d r d 2$-eGFP mice, in which the iSPNs were identified by GFP fluorescence. Putative dSPNs were identified by lack of GFP fluorescence. For selected experiments slices were pretreated with $10 \mu \mathrm{M}$ AM251 in aCSF with BSA for $1 \mathrm{~h}$ before HFS. JZL184 $(10 \mu \mathrm{M})$ and URB597 $(1 \mu \mathrm{M})$ treatment was also incubated for $1 \mathrm{~h}$ before HFS.

Depolarization-induced suppression of excitation. The intracellular solution was potassium based as follows (mM): 145 potassium gluconate, $1 \mathrm{MgCl}_{2}$, 2 MgATP, 0.5 NaGTP, 1 EGTA, 10 HEPES, pH 7.3, 280-290 mosmol $/ \mathrm{L}^{-1}$. Test pulses were delivered at $0.2 \mathrm{~Hz}$ by an aCSF filled pipette in the striatum dorsal to the SPNs. After 2 min of stable baseline, the cell was depolarized to $+30 \mathrm{mV}$ for $10 \mathrm{~s}$ and the current response was recorded for an additional $2 \mathrm{~min}$. This protocol was repeated two or three times and normalized responses were averaged for each cell. Summary data show the EPSC immediately following depolarization to show the magnitude of suppression. To show CB1 dependence slices were pretreated for 30 min or more with $5 \mu \mathrm{M}$ AM251 in the aCSF and compared with vehicle control.

Preparation and immunostaining of brain slices. Male YAC128 (line 53) mice and WT littermates (1-2 months old) were killed with an intraperitoneal injection of euthanyl (pentobarbital sodium USP $240 \mathrm{mg} / \mathrm{ml} ; 2$ $\mathrm{ml} / 4.5 \mathrm{~kg}$ of body weight) and were perfused through the cardiovascular system with $0.1 \mathrm{~m}$ phosphate buffer solution (0.1 M PBS, pH 7.4), followed by a solution of $4 \%$ paraformaldehyde (PFA) $/ 4 \%$ sucrose in $0.1 \mathrm{M}$ PBS. The brains were then removed and placed in $4 \% \mathrm{PFA} / 4 \%$ sucrose overnight at $4^{\circ} \mathrm{C}$, then transferred to $0.1 \mathrm{M}$ PBS and stored again overnight at $4^{\circ} \mathrm{C}$. They were then transferred to a solution of $30 \%$ sucrose in $0.01 \mathrm{~m}$ PBS. Coronal sections ( $40 \mu \mathrm{m}$ thick) including dorsolateral striatum were prepared using frozen sectioning (HM525 NX Cryostat; ThermoFisher Scientific). The slices were then stained as described previously 
A
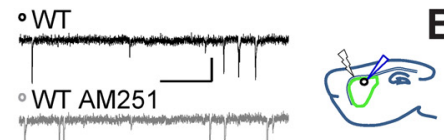

B
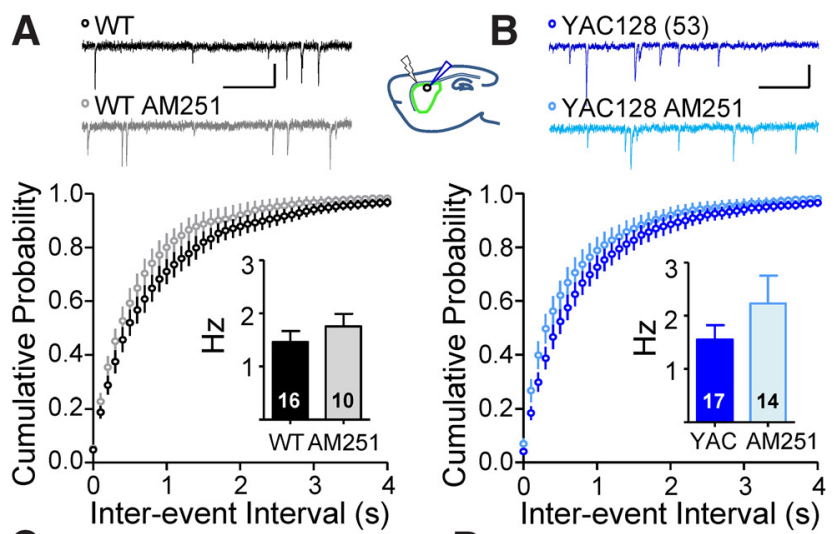

C
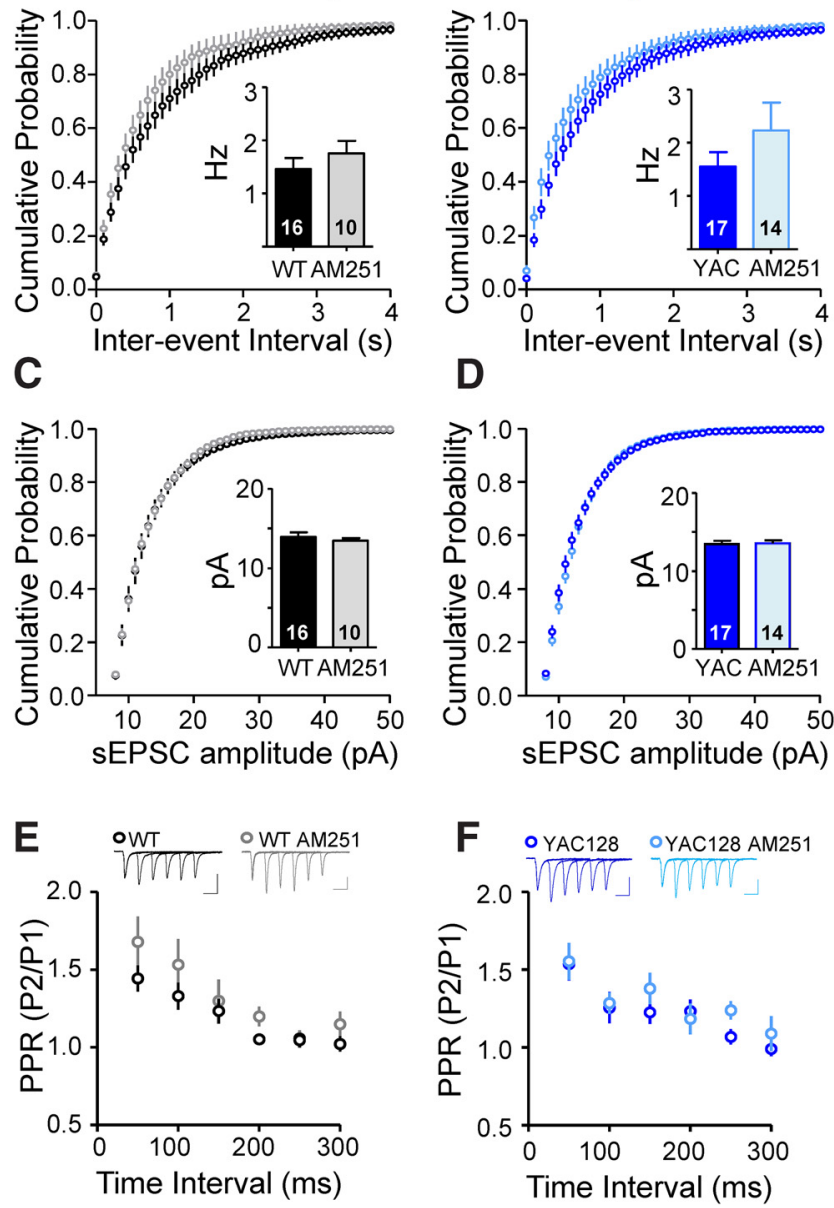

Figure 3. CB1 basal activation is unchanged in YAC128. sEPSC frequency after AM251 to block CB1 in WT $(\boldsymbol{A})$ and YAC128 (B) representative traces with or without $10 \mu \mathrm{M} \mathrm{AM} 251$ for $1 \mathrm{~h}$. Scale bar, $10 \mathrm{pA}, 500 \mathrm{~ms}$. Cumulative probability distribution of sEPSC interevent intervals with mean frequency in hertz (inset). Left shift indicated shorter interevent intervals after AM251 in both WT $[n=16(6)$ and AM251 $n=10(4)]$ and YAC128 SPNs $[n=17(9)$ and AM251 $n=$ 14(8)]. C, WT and (D) YAC128 sEPSC amplitudes show no difference by cumulative probability plots or group mean (inset). $\boldsymbol{E}$, WT and $(\boldsymbol{F})$ YAC128 summary showing the paired-pulse ratios in untreated SPNs and SPNs after AM251 was not significantly different in WT $[n=9(3)$ and $6(3)$, respectively] or YAC128 [ $n=11(7)$ and 6(4)]. Scale bar, $100 \mathrm{pA}, 50 \mathrm{~ms}$.

(Wu et al., 2015). Briefly, slices were transferred to PBS, then incubated with $10 \%$ normal goat serum (NGS) in PBS with $0.5 \%$ Triton-X (PBS-T; Sigma-Aldrich) for $30 \mathrm{~min}$ at room temperature. They were then incubated with a mixture of rabbit anti-CB1 (1:200; Bodor et al., 2005) and guinea pig anti-VGluT1 (1:500; Millipore) in 2\% NGS in PBS-T for $1 \mathrm{~h}$ at room temperature and then overnight at $4^{\circ} \mathrm{C}$. The slices were then washed three times with PBS-T. They were then incubated with a mixture of AlexaFluor 568-conjugated goat anti-rabbit (1:500; Invitrogen) and AlexaFluor 488-fused goat anti-guinea pig (1:500; Invitrogen) in $2 \%$ NGS in PBS-T for $2 \mathrm{~h}$ at room temperature. The slices were then washed three times with PBS-T and mounted on slides.

\section{Imaging and puncta analysis}

Images were acquired with a Leica SP8 confocal microscope. Sections of dorsal striatum were imaged at $63 \times$ magnification (oil-immersion, 1.4 NA). VGluT1 was imaged using an excitation wavelength of $493 \mathrm{~nm}$ and a detection wavelength of $519 \mathrm{~nm}$. CB1 was imaged using an excitation wavelength of 578 and a detection wavelength of 603 . Emitted photons were detected using a Leica HyD hybrid detector. A single image was taken from the dorsolateral striatum of each of three separate slices per mouse. Each image was $1024 \times 1024$ pixels, with each pixel measuring $0.1 \mu \mathrm{m} \times 0.1 \mu \mathrm{m}$. The images files were then imported into ImageJ for analysis. First the background was subtracted from each channel using a sliding paraboloid 5 pixels in radius using the ImageJ Subtract Background tool to remove low spatial frequencies, and then a threshold was set manually to remove low intensity nonspecific staining while preserving puncta staining. All thresholding was done with genotypes interleaved and the experimenter blinded to genotype. The binary thresholded images were then analyzed for puncta size, density, and colocalization using the Analyze Particles tool and colocalization plugin for ImageJ. Puncta were defined as groups of contiguous pixels which were above threshold in both channels-of-interest (red for CB1, green for VGluT1). Colocalization was quantified using the colocalization plugin for ImageJ (https:/ imagej.nih.gov/ij/plugins/colocalization.html). The plugin overlaid the binary images of the red and green channels. Colocalized puncta were defined as contiguous pixels which were above threshold in both the red and green channels.

Channelrhodopsin expression. YAC128 mice from line 53 and their WT littermates at 1 month of age were injected with adeno-associated virus serotype 9 carrying fusion genes for channelrhodopsin 2 (ChR2) and yellow fluorescent protein (AAV9-ChR2-h134-YFP) under the synapsin promoter, produced by PennVector Core with titer 3.39e13 GC/ml. Viral particles were delivered through a glass micropipette attached to a Hamilton microliter syringe and Micro Syringe Pump Controller (Micro4, WPI). The tip of the pipette was advanced $0.5 \mathrm{~mm}$ ventral and then retracted to coordinates indicated before delivery of virus at $1 \mathrm{nl}$ per second followed by a $10 \mathrm{~min}$ wait to ensure solution diffused below the injection site. For thalamostriatal experiments, $1 \mu \mathrm{l}$ was injected with coordinates from bregma $2 \mathrm{~mm}$ posterior, $0.8 \mathrm{~mm}$ lateral, and $2 \mathrm{~mm}$ ventral to the surface of the brain. For corticostriatal experiments, $0.5 \mu \mathrm{l}$ was injected with coordinates $1.0 \mathrm{~mm}$ lateral, $1.5 \mathrm{~mm}$ anterior to bregma, and $0.5 \mathrm{~mm}$ ventral from the brain surface. After 2-3 weeks of recovery, acute coronal brain slices were prepared as described above and viral expression at the injection site was visually confirmed by YFP expression. Coronal slice orientation was used to optimize the number of slices with significant ChR2 expression on afferents to the striatum. Optical stimulation of corticostriatal and thalamostriatal afferents was performed using a $470 \mathrm{~nm}$ LED (CoolLed-pE excitation system) mounted on a Zeiss Axioexaminar microscope to give $0.5 \mathrm{~ms}$ duration light pulses of $\sim 5$ $\mathrm{mW}$. The spot size corresponded to the area of the slice visualized using a $40 \times / 0.8$ NA water-immersion objective. Half-maximal evoked EPSC were recorded at $0.06 \mathrm{~Hz}$ and moderate frequency stimulation for LTD consisted of $5 \mathrm{~min}$ at $10 \mathrm{~Hz}$.

\section{Experimental design and statistical analysis}

All data represents the mean \pm SEM of $n=$ number of neurons for whole-cell or slices for field recordings with the number of animals indicated in brackets. All experimental groups include males and females (with the exception of immunohistochemistry and LTD in male only 6-month-old WT and YAC128; Figs. 2, 4E, F). A minimum of three mice per group were used at the age indicated in the text. Analysis was performed using Clampfit 10.4 (Axon instruments) and Prizm 5 (Graph$\mathrm{Pad}$ ). Statistical analyses are indicated in detail in the results section with $p<0.05$ considered significant and were made by student two-tailed $t$ test or two-way ANOVA. Comparisons of PPR before and after LTD were analyzed by paired $t$ test.

\section{Results}

\section{HFS-LTD attenuated in YAC128 striatum}

Excitatory field potentials (fEPSPs) were evoked every $15 \mathrm{~s}$ in the dorsolateral striatum by stimulation in the white matter dorsal to the striatum to selectively activate cortical afferents in brain slices from 2-month-old YAC128 (line 55 homozygous) and WT FVB/N mice. $\mathrm{GABA}_{\mathrm{A}}$ receptors were blocked with $50 \mu \mathrm{M}$ Picrotoxin in the aCSF for all experiments. After a minimum of 5 min stable baseline, HFS ( $100 \mathrm{~Hz}$ for $1 \mathrm{~s}$, repeated 4 times at $10 \mathrm{~s}$ intervals) was applied. In WT striatum, HFS resulted in a decrease in the 
amplitude of the fEPSP that lasted $>40 \mathrm{~min}$ (Fig. $1 A, B$ ). YAC128 striatal field responses showed no decrease in amplitude after HFS compared with WT $\left(t_{(12)}=2.58,{ }^{*} p=0.0238, t\right.$ test, $n=6$ and 8 YAC128 and WT mice, respectively). The PPR of stimuli at a $50 \mathrm{~ms}$ interval was measured before and $35 \mathrm{~min}$ after HFS (Fig. $1 C$; pre- and post-HFS, respectively) as indicative of a presynaptic change in the probability of glutamate release. The PPR was significantly increased after HFS in WT (Fig. $1 C ; t_{(5)}=2.44,{ }^{*} p=$ 0.0292 , paired $t$ test), but there was no change in the PPR in YAC128 $\left(t_{(7)}=1.37, p=0.1059\right.$, paired $t$ test).

LTD was then tested by whole-cell patch-clamp recordings that are more sensitive to changes in synaptic efficacy. In the dorsolateral striatum, randomly selected SPNs were examined in brain slices from WT and YAC128 mice at 4 weeks of age, well before development of an overt HD phenotype, to determine whether synaptic plasticity changes could be observed at this early stage. LTD was reliably evoked by HFS paired with depolarization to $0 \mathrm{mV}$ in WT SPNs, which showed a profound reduction in EPSC amplitude compared with baseline that persisted for $>40$ min (Fig. 1D). In YAC128 SPNs, however, only a modest reduction in EPSC amplitude was observed that did not persist. At 35 min after HFS, YAC128 SPNs showed significantly less depression than WT SPNs [Fig. $1 D, E$; WT $n=12(10)$ and YAC128 $n=$ $7(7) ; t_{(17)}=3.419,{ }^{* *} p=0.0033, t$ test]. In WT SPN there was a significant increase in PPR after HFS $\left(t_{(11)}=6.147,{ }^{* * *} p=\right.$ 0.0001 , paired $t$ test), but YAC128 SPN showed no change in PPR $t_{(6)}=0.2145, p=0.8372$, paired $t$ test $)$.

To determine whether the deficit in HFS-LTD is due to mutant huntingtin expression, HFS-LTD was also tested in the ZQ175FDN(Q175) model of HD (Southwell et al., 2016). At 2 months of age, Q175 SPNs showed attenuated LTD compared with SPNs from WT littermates [Fig. $1 G-I ; t_{(9)}=3.397,{ }^{* *} p=0.0079, t$ test, WT $n=4(3)$ and Q175 $n=7(4)$ ]. Consistent with the YAC128 model of HD, WT SPNs showed an increase in PPR after HFS $\left(t_{(3)}=\right.$ $4.805,{ }^{*} p=0.0172$, paired $t$ test), whereas Q175 SPNs showed no change in $\operatorname{PPR}\left(t_{(7)}=0.946, p=0.3754\right.$, paired $t$ test $)$.

Previous studies show that LTD evoked by HFS in the striatum is mediated by endocannabinoids acting at CB1 (Kreitzer and Malenka, 2005; Ade and Lovinger, 2007). The attenuation of HFS-LTD in YAC128 and Q175 SPN could be due to a decrease in the expression or function of CB1 at corticostriatal synapses.

\section{CB1 expression is unchanged at excitatory synapses onto striatal neurons}

The level of CB1 expression was compared between YAC128 and WT striatum using immunohistochemistry in brain slices. There was no difference in the density of CB1 puncta between WT and YAC128 $\left[t_{(16)}=0.0799, p=0.9372 ; t\right.$ test, WT and YAC128 $n=$ 9(3); Fig. 2A-E]. To examine CB1 specifically at excitatory synapses, glutamatergic synapses were identified by immunoreactivity for presynaptic vesicular glutamate transporter 1 (VGluT1). The percentage of CB1 puncta that colocalized with VGluT1 was unchanged in YAC128 striatum $\left(t_{(16)}=0.1873, p=0.8538, t\right.$ test), suggesting that CB1 expression is preserved at corticostriatal synapses in these mice at this age.

\section{Basal levels of CB1 activity are similar in WT and YAC128 corticostriatal synapses}

If the basal level of endocannabinoids or the activity of CB1 was already high in the striatum of YAC128, it could occlude other endocannabinoid-mediated processes such as LTD. In that case, blocking the $\mathrm{CB} 1$ receptor would have a more dramatic effect on the probability of glutamate release in YAC128(53) SPNs than WT
SPNs. To that end we measured the frequency of sEPSCs in untreated, randomly-selected SPNs and SPNs preincubated with 10 $\mu \mathrm{M}$ AM251 for $>1 \mathrm{~h}$ in both YAC128 and WT brain slices from 1-month-old mice (Fig. 3A-D). A direct comparison of untreated WT and YAC128 SPNs showed no difference in the basal sEPSC frequency in $\mathrm{Hz}$ [ $1.17 \pm 0.14 \mathrm{WT} n=16(6)$ vs $1.34 \pm 0.25 \mathrm{YAC} 128$ $n=17(9) ; t_{(31)}=0.2781, p=0.7828, t$ test $]$ or amplitude (13.91 \pm $0.58 \mathrm{pA}$ vs $13.45 \pm 0.41 \mathrm{pA} ; t_{(31)}=0.6656, p=0.5169, t$ test $)$.

After AM251 treatment there was no difference in the mean frequency of sEPSC in Hz in WT [Fig. 3A, inset; $t_{(24)}=0.9061$, $p=0.1869 t$ test; WT untreated $n=16(6)$ and WT AM251 treated $n=10(4)$ ] or YAC128 SPNs [Fig. $3 B$, inset; $t_{(29)}=1.211$, $p=0.1178, t$ test, YAC128 untreated $n=17(9)$ and YAC128 AM251 treated $n=14(8)]$. There was also no change in amplitude after AM251 in WT (Fig. 3C; $t_{(24)}=0.6013, p=0.2766, t$ test) or YAC128 (Fig. $3 D ; t_{(29)}=0.1473, p=0.4419, t$ test). The cumulative probability of interevent intervals showed that AM251 caused a shift to the left, suggesting increased shorter intervals indicating enhanced glutamate release probability with $\mathrm{CB} 1$ antagonism (Fig. $3 A, B$ ); however, this change appeared similar in YAC128 and WT SPNs. A change in the cumulative distribution that is not reflected in the mean could indicate an increase in events that occur in bursts. The PPR at intervals of $50-300 \mathrm{~ms}$ was also tested (Fig. $3 E, F$ ). There was no significant difference in PPR after AM251 treatment for either genotype $\left[F_{(5,78)}=0.43\right.$, $p=0.8241$, two-way ANOVA; WT untreated $n=9(3)$ and WT AM251 treated $n=6(3) ; F_{(5,88)}=0.43, p=0.8278$, two-way ANOVA; YAC128 untreated $n=11(7)$ and YAC128 AM251 $n=$ 6(4)]. The basal PPR in these experiments was not different between untreated WT and YAC128 SPNs at any interval $\left(F_{(5,108)}=\right.$ $0.76, p=0.5787$, two-way ANOVA).

\section{Impairment in HFS-LTD is selective for cortical synapses onto D2-expressing iSPNs}

In contrast to the consistent LTD observed in WT SPNs, not all YAC128 SPNs exhibited a decrease in EPSC amplitude in response to HFS. Some studies show that eCB-mediated LTD is more likely to be observed in iSPNs compared with dSPNs (Kreitzer and Malenka, 2007) although other studies show LTD to be expressed in both cell types (Wang et al., 2006). It has also been reported that iSPNs show synaptic deficits before dSPNs in HD (Plotkin and Surmeier, 2015). WT FVB/N and YAC128 (line 55) crosses with homozygous $\operatorname{Tg}(\mathrm{Drd} 2-\mathrm{EGFP})$ on a FVB/N background were used here to assess LTD in identified iSPNs (expressing GFP) and putative dSPNs (unlabeled).

In YAC128 putative dSPNs, HFS-LTD was not significantly different from in WT FVB/N dSPNs $(62.09 \pm 5.869 n=4$ YAC128 mice vs $69.48 \pm 7.908 \% n=6$ WT mice of initial EPSC amplitude, $t_{(8)}=0.6769, p=0.5175, t$ test). In contrast, in iSPNs, LTD 35 min post-HFS was significantly attenuated in YAC128 compared with WT FVB/N mice (Fig. $4 A, B ; n=5 \mathrm{YAC} 128$ mice and $n=6 \mathrm{WT}$ mice; $t_{(9)}=3.759,{ }^{* *} p=0.0045, t$ test). Consistent with an impaired response to HFS, the PPR of YAC128 iSPNs was unchanged after HFS (Fig. $4 C ; t_{(4)}=0.2504, p=0.4073, t$ test) compared with the increase in PPR observed in WT iSPNs (Fig. $4 C ; t_{(5)}=3.324,{ }^{*} p=0.0105$, paired $t$ test). Moreover, inhibition of CB1 receptors by AM251 (10 $\mu \mathrm{M})$ blocked LTD in WT iSPNs [Fig. $4 D ; t_{(14)}=5.627,{ }^{* * *} p=0.0001, t$ test, WT untreated $n=$ 11(10) and AM251 treated $n=5(5)]$, and blocked the post-HFS change in PPR $(1.118 \pm 0.123 n=5$ pre-HFS vs $1.152 \pm 0.107$ $n=5$ post-HFS; $t_{(4)}=1.1610, p=0.0913$, paired $t$ test). The deficit in HFS-LTD for YAC128(55) iSPNs was even more profound at 6 months of age (Fig. $4 E, F ; t_{(8)}=4.252,{ }^{\star *} p=0.0028, t$ test; $n=$ 
A

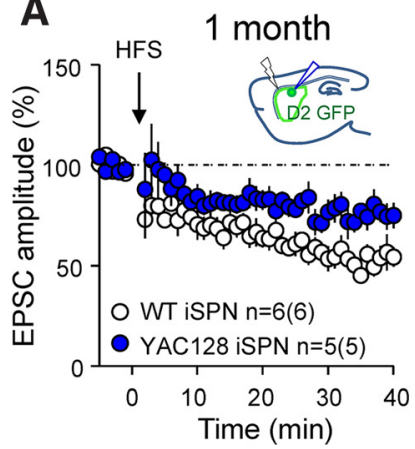

D

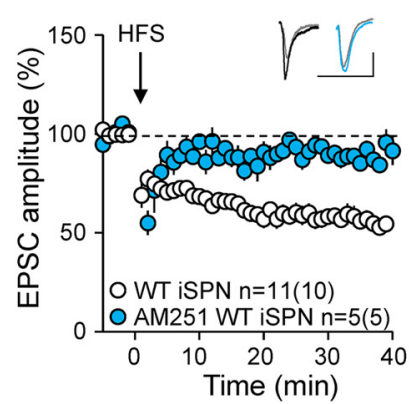

B
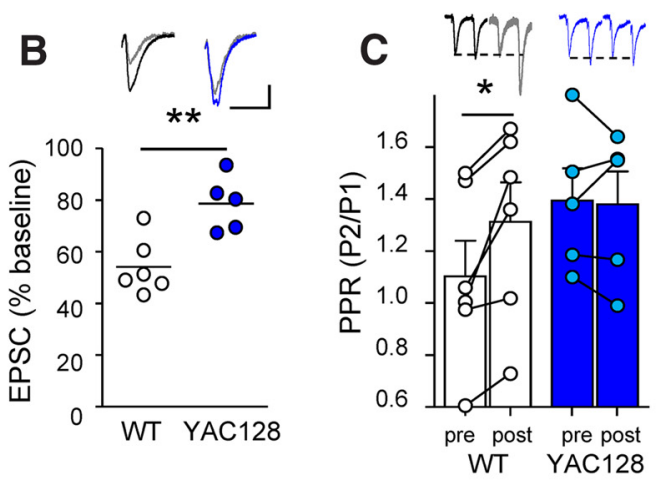

E

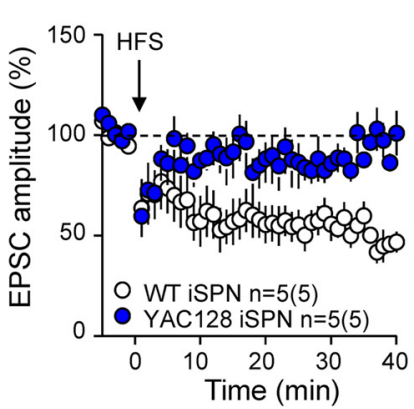

Figure 4. Impaired LTD in YAC128 iSPNs. A, Averaged time course of normalized EPSC amplitude after applying HFS and depolarization at time 0 in 1-month-old WT and YAC128 in iSPNs labeled with eGFP. Inset, Sagittal slice with recording of eGFP-positive iSPN in the dorsal striatum. $\boldsymbol{B}$, Mean responses showing significantly greater reduction in WT iSPNs than YAC128. ${ }^{* *} p=0.0045$ Representative traces pre- and post-HFS in WT (left) and YAC128 (right). Scale bar, 100 pA, 50 ms. C, PPR of EPSCs is increased in WT iSPNs but not YAC128 iSPNs 35 min after induction of LTD (post) compared with baseline (pre). ${ }^{*} p=0.0105$, Time course summary showing block of HFS-LTD in iSPNs after application of $10 \mu \mathrm{M}$ AM251. $E$, Time course summary of iSPNs from 6-month-old WT and YAC128 showing normalized EPSC amplitude after HFS. F, Mean responses showing significantly larger reduction in WT compared with YAC128 iSPNs. ${ }^{* *} p=0.0028$.

5 YAC128 male mice and $n=5$ WT male mice), suggesting a progressive impairment in capacity for eCB-mediated LTD at these corticostriatal synapses in HD mice.

\section{Moderate frequency-induced LTD $(10 \mathrm{~Hz})$ remains intact in YAC128 SPNs}

Projections from the thalamus also contribute excitatory input to the striatum and the capacity of YAC128 striatum to exhibit presynaptic long-term depression at thalamostriatal synapses is unknown. To differentiate the cortical and thalamic afferents to the striatum we injected a viral vector for expression of channel rhodopsin (AAV9-ChR2-H134R-YFP) in the thalamus or in the cortex of 1-month-old WT and YAC128(53). After 2-3 weeks, brain slices were taken that contained the striatum and glutamatergic axons were selectively activated by blue LED light. LTD was induced by moderate-frequency $(10 \mathrm{~Hz}$ for $5 \mathrm{~min}$ ) stimulation (more amenable to ChR2 activation kinetics than HFS) after a stable baseline to evoke approximately half-maximal EPSC size that was not different between WT and YAC128. In response to this moderate frequency light pulse stimulation of either ChR2expressing thalamic or cortical afferents, EPSC amplitudes were dramatically reduced in both WT and YAC128 SPNs, and the change persisted for $>40$ min (Fig. $5 A, B$ ). The PPR was not compared in these experiments due to greater variability of PPR in ChR2-evoked EPSCs compared with electrically-evoked EPSCs. Interestingly, there was a transient increase in EPSC amplitude immediately following the $5 \mathrm{~min} 10 \mathrm{~Hz}$ stimulation of thalamic afferents that was significantly greater in YAC128 than
$\mathbf{F}$

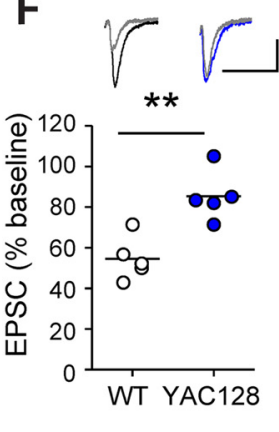

WT SPNs $(225.0 \pm 19.08 n=4$ vs $133.20 \pm 1.44 n=4$ respectively; $t_{(2)}=$ $4.795,{ }^{*} p=0.0408, t$ test $)$ suggesting that thalamostriatal synapses are also affected by $\mathrm{mHtt}$ expression, as recently shown by Kolodziejczyk and Raymond (2016) and Parievsky et al. (2017). The moderate frequency stimulation shows that presynaptic signaling pathways involved in longterm suppression of glutamate release are preserved in YAC128 SPNs at both corticostriatal and thalamostriatal synapses.

Thalamostriatal synapses, however, do not express CB1 (Uchigashima et al., 2007; $\mathrm{Wu}$ et al., 2015) so the moderate frequency induced LTD would be expressed by a different mechanism. Consistent with previous studies (Kreitzer and Malenka, 2005) presynaptic mGluRs were implicated when LTD induced by $10 \mathrm{~Hz}$ electrical stimulation was abolished by pretreatment with the Group I/II mGluR antagonist LY341495 [60 $\mu$ m; Fig. 5C-E; $t_{(8)}=2.423,{ }^{*} p=0.0208, t$ test; $n=5(3)$ untreated neurons from WT and $n=5(4)$ neurons treated with LY341495]. In WT SPNs the PPR increased consistent with a presynaptic expression of LTD $\left(t_{(4)}=\right.$ $3.068,{ }^{*} p=0.0187$, paired $t$ test) and this increase was abolished by the mGluR antagonist $\left(t_{(4)}=2.080, p=0.053\right.$, paired $t$ test). Similarly to CB1, presynaptic mGluR2/3 in the striatum are G-proteincoupled and reduce transmitter release by inhibition of adenylyl cyclase and cAMP production. The expression of $10 \mathrm{~Hz}$ LTD in YAC128 SPN suggests normal signaling of pathways downstream of $\mathrm{CB} 1$. To test this more directly we applied CB1 agonists to suppress glutamate release. WT and YAC128 showed equivalent reduction in fEPSP amplitude in response to WIN55,212-2 (Fig. $5 F, G$; $t_{(9)}=0.6708, p=0.5192, t$ test; $n=5$ WT and $n=6$ YAC128 mice). The CB1 agonist, CP55,940, also reduced fEPSP similarly in WT and YAC128 (Fig. $5 \mathrm{H}, \mathrm{I} ; t_{(17)}=0.2846, p=0.7794, t$ test $n=10 \mathrm{WT}$ and $n=9 \mathrm{YAC} 128$ mice).

\section{2-AG-mediated depolarization-induced suppression of excitation remains intact in YAC128 striatal SPNs}

Although presynaptic CB1 signaling at corticostriatal synapses in YAC128 is unchanged, our results could be explained if YAC128 SPNs were deficient in the ability to synthesize eCBs. Short-term plasticity mediated by the endocannabinoid 2-AG, called depolarization-induced suppression of excitation (DSE), can be induced in SPNs by depolarization to $+30 \mathrm{mV}$ for $10 \mathrm{~s}$ (Shonesy et al., 2013). A comparison of brain slices from YAC128(55) versus WT mice at 1 month of age showed that the magnitude of the reduction in EPSC amplitude during DSE in randomly selected SPNs is the same in both genotypes [Fig. $6 A, B ; t_{(14)}=$ $1.408, p=0.1810, t$ test; WT $n=7(6)$ and YAC128 $n=9(5)]$.

To address whether DSE is sensitive to $\mathrm{mHtt}$-load we tested SPNs that express higher levels of mHtt from 1-month-old YAC128 line 53 heterozygotes and their WT littermates. Using the same protocol, we found DSE equally expressed in YAC128(53) and WT SPNs [Fig. $6 C ; t_{(20)}=0.4199, p=0.6790, t$ test; WT $n=10(4)$ and YAC128 
$n=12(7)]$. In separate experiments, we incubated YAC128(53) slices with the CB1 antagonist AM251 to confirm the CB1 dependence of the reduction in EPSC amplitude. DSE was abolished in SPNs treated with $5 \mu \mathrm{M}$ AM251 for $>30 \mathrm{~min}$ compared with untreated SPNs, indicating that DSE in YAC128(53) SPNs is CB1dependent [Fig. $6 D ; t_{(11)}=5.713,{ }^{* *} p=$ $0.0001, t$ test; YAC128 untreated $n=6(3)$ and YAC128 AM251 treated $n=7(3)]$. To determine whether DSE is altered at a later disease stage, when motor impairments are observed, we tested YAC128 (line 55) at 6 months of age. In WT FVB/N SPNs at 6 months, mean DSE magnitude was similar to that observed for WT FVB/N at 1 month of age (Fig. $6 B, E$ ). In YAC128 at 6 months, mean DSE magnitude was identical to WT [Fig. $6 E ; t_{(10)}=0.5382, p=$ 0.6022 , WT and YAC128 $n=6(3)]$. To determine whether DSE could be modulated by increasing 2-AG levels in dorsal striatal SPNs we preincubated slices for $1 \mathrm{~h}$ with the monoacylglycerol lipase (MAGL) inhibitor JZL184 (1 $\mu \mathrm{M})$. WT SPNs treated with JZL184 showed a potentiation of DSE compared with untreated SPNs [first response $69.01 \pm 4.10 \%$; baseline $n=8(3)$ JZL-treated neurons vs $82.08 \pm 4.31 \% n=7(3)$ untreated neurons; $t_{(13)}=2.197,{ }^{*} p=0.0234, t$ test, data not shown].

The similarity of DSE in YAC128 compared with WT demonstrated that shortterm, 2-AG-mediated activation of CB1 was independent of mHtt expression and disease stage. The discrepancy between the efficacy of DSE and the impairment of endocannabinoid-mediated HFS-LTD in YAC128 could be due to alterations in signaling downstream of CB1 activation that impair long-term changes in glutamate release. CB1 efficacy was then tested by long-term plasticity induced by the Group I mGluR agonist DHPG and mediated by 2-AG (Kreitzer and Malenka, 2005; Tanimura et al., 2010). DHPG (50 $\mu \mathrm{M})$ bath applied for $10 \mathrm{~min}$ evokes a long-term reduction in EPSC amplitude in both WT and YAC128 iSPN held at $-50 \mathrm{mV}$ [Fig. $6 F-H ; t_{(15)}=0.6109, p=0.5504, t$ test; $\mathrm{WT} n=10(8)$ and YAC128 $n=7(6)]$ and the PPR after DHPG is increased for both genotypes (Fig. $6 H$. WT ${ }^{\star} p=0148$ and YAC128 ${ }^{\star} p=0.0124$, paired $t$ test). The presence of LTD in both WT and YAC128 iSPN suggests that short- and long-term plasticity mediated by $2-\mathrm{AG}$ are preserved in YAC128 in contrast to HFS-LTD.

\section{High-frequency-induced LTD in YAC128 iSPNs is rescued by upregulating 2-AG levels}

Although DSE mediated by 2-AG is unchanged, the attenuation of HFS-LTD in YAC128 could be due to a deficit in anandamide signaling (Ade and Lovinger, 2007; Kreitzer and Malenka, 2007; extent in WT and YAC128 striatum.
B

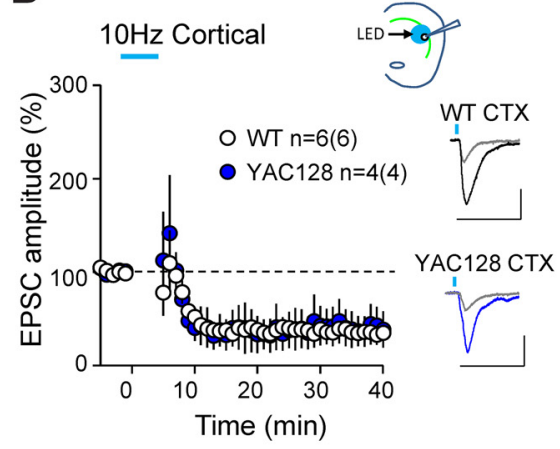

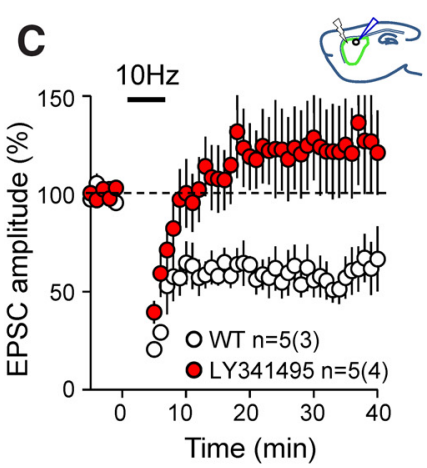

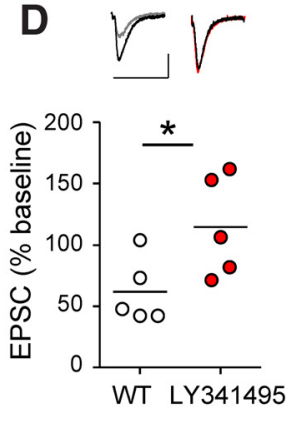

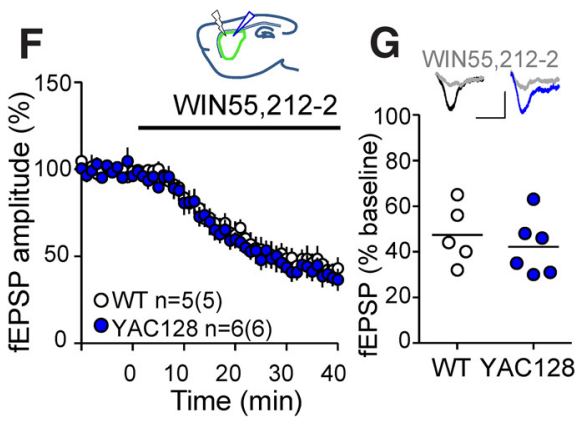
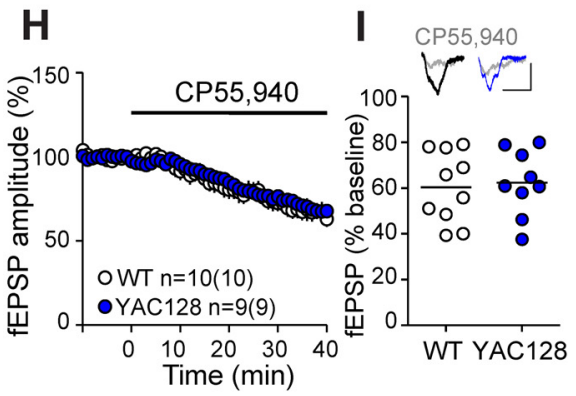

Figure 5. Presynaptic mGluR2/3-mediated moderate frequency LTD and direct agonism of CB1 intact in YAC128 mice. $\boldsymbol{A}, A$ veraged time course and representative traces showing ChR2-evoked EPSC from thalamus normalized to baseline and after stimulation at $10 \mathrm{~Hz}$ for 5 min showing a decrease in EPSC amplitude that was not significantly different between WT and YAC128 striatum. There was a transient increase in response size after $10 \mathrm{~Hz}$ stimulation. Inset, Coronal hemisection with recording of SPN in dorsal striatum and blue LED spot to activate ChR2. B, Averaged time course and representative traces showing ChR2-evoked EPSC from cortex normalized to baseline and after stimulation at $10 \mathrm{~Hz}$ for $5 \mathrm{~min}$, showing a decrease in EPSC amplitude that was not significantly different between WT and YAC128 SPN. Scale bar, 200 pA, 50 ms. C, Averaged time course showing EPSC before/after $10 \mathrm{~Hz}$ stimulation of cortical inputs for 5 min in untreated WT SPNs and LY341495-treated WT SPNs to block mGluR2/3. D, Summary showing normalized EPSC amplitudes after $10 \mathrm{~Hz}$ stimulation are significantly lower in untreated WT SPNs compared with SPNs treated with LY341495. ${ }^{*} p=0.0208 E$, PPR before and 30 min after $10 \mathrm{~Hz}$ stimulation is increased in untreated WT SPN but not SPNs treated with LY341495. ${ }^{*} p=0.0187 \boldsymbol{F}$, Averaged time course showing application of WIN55,212-2 reduced fEPSPs normalized to baseline. G, Summary and representative traces showing fEPSP amplitudes are reduced by $10 \mu \mathrm{m}$ WIN55,212-2 to the same extent in WT and YAC128 striatum. $\boldsymbol{H}$, Averaged time course showing application of $5 \mu \mathrm{M}$ CP55,940 reduced fEPSPs normalized to baseline. I, Summary and representative traces showing fEPSP amplitudes are reduced by CP55,940 to the same

Lerner and Kreitzer, 2012). First we showed that 1-month-old YAC128 iSPNs from line 53 (with greater mHtt expression) showed an attenuation of HFS-LTD compared with iSPNs of WT littermates [Fig. $7 A ; t_{(18)}=2.146,{ }^{\star} p=0.0457, t$ test; WT $n=$ $11(10)$ and YAC128 $n=9(9)]$. As shown in Figure $1 D$, acute inhibition of CB1 in striatal slices resulted in an attenuation of HFS-LTD in WT SPNs, suggesting that the LTD deficit in YAC128 SPNs could be the result of impaired anandamide-mediated CB1 activation. We tested whether HFS-LTD in YAC128 SPNs could be enhanced by raising anandamide levels 

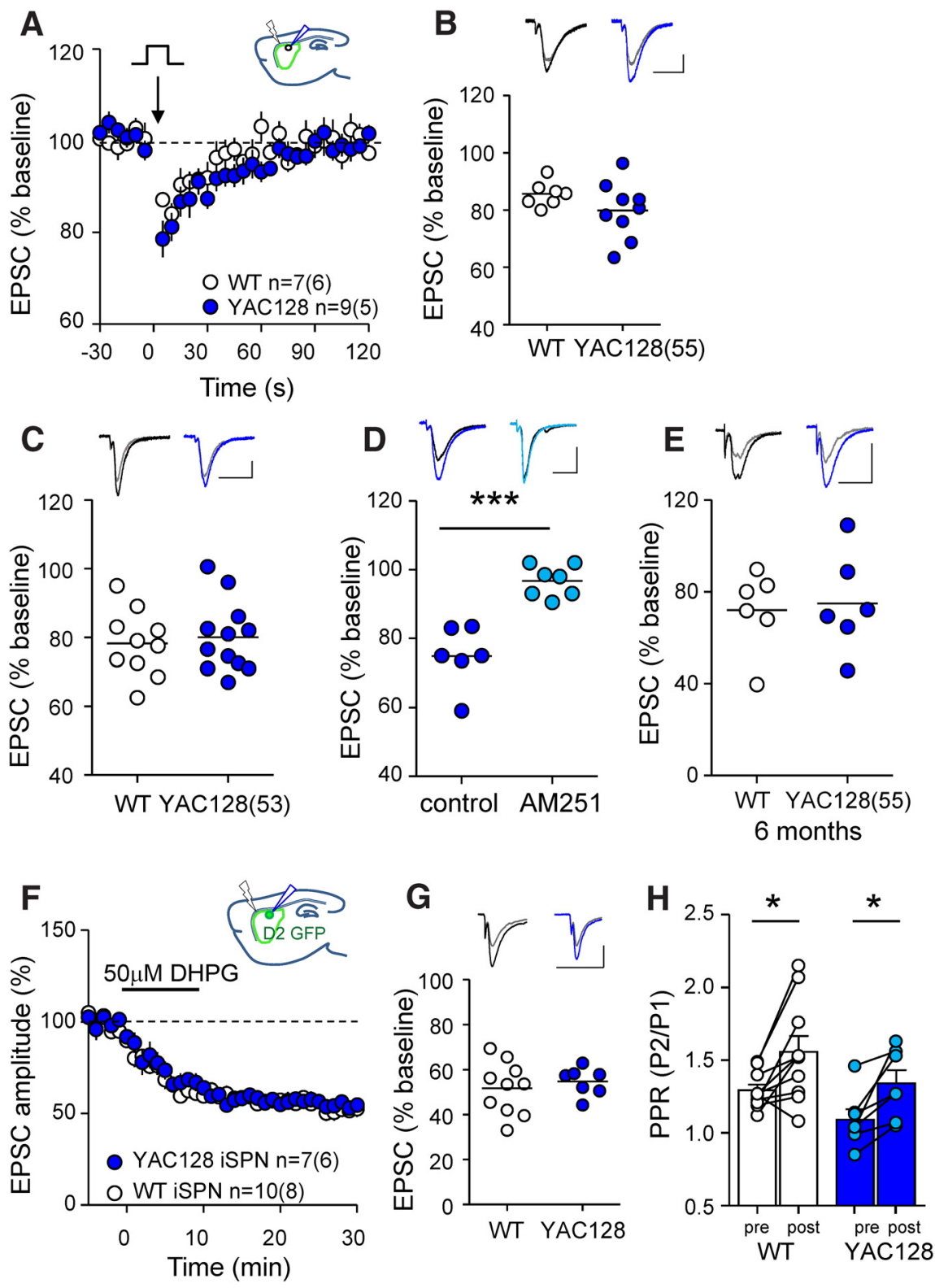

Figure 6. DSE and mGluR1/5 activation are unchanged in YAC128 SPNs. $A$, Time course summary of EPSC in randomly selected SPNs before and after depolarization to $+30 \mathrm{mV}$ for $10 \mathrm{~s}$ (arrow) in 1-month-old WT and YAC128 (line 55). B, Summary of WT and YAC128 SPNs normalized EPSC response immediately after depolarization. Representative traces show baseline before (WT, black; YAC128, blue) and after (gray). Reduction in EPSC amplitude in YAC128 is not significantly different from WT. C, DSE summary in SPNs of line 53 YAC128 [YAC128(53)] with greater mHtt expression $[n=12(7)]$ and their WT littermates [WT, $n=10(4)]$. Reduction in EPSC amplitude in YAC128 is not significantly different from WT. D, Summary and representative traces in SPNs of YAC128 showing near-elimination of DSE after pretreatment with $C B 1$ antagonist $[n=7(3)$; light blue $]$ compared with untreated SPNs (vehicle control, $n=6(3)$; dark blue]. ${ }^{* * *} p=0.0001 E$, DSE summary of 6-month-old YAC128(55) $[n=6(3)]$ and WT $[n=$ 6(3)]. Reduction in EPSC amplitude in YAC128 is not significantly different from WT SPNs. $F$, Time course summary showing normalized EPSC amplitudes in iSPN held at $-50 \mathrm{mV}$ with application of $50 \mu \mathrm{m}$ DHPG for $10 \mathrm{~min}$ (black bar). G, Summary and representative traces showing EPSC amplitude $20 \mathrm{~min}$ after DHPG is not different between WT and YAC128 SPNs. H, PPR of EPSC is increased in both WT ${ }^{*} p=0.0148$ and YAC128 iSPN after DHPG. ${ }^{*} p=0.0124$.

with the fatty acid amide hydrolase (FAAH) inhibitor URB597. YAC128(53) iSPNs preincubated for $1 \mathrm{~h}$ with $1 \mu \mathrm{M}$ URB597 showed no significant difference in HFS-LTD compared with untreated YAC128(53) iSPNs [Fig. $7 B, C$; $t_{(13)}=0.7883, p=0.446, t$ test; YAC128 $n=9(9)$ and URB597 treated YAC128 $n=6(4)]$. We then tested HFS-LTD in the presence of the inhibitor of MAGL, JZL184, to increase levels of 2-AG. YAC128(53) iSPNs preincubated with $10 \mu \mathrm{M}$ JZL184 for $1 \mathrm{~h}$ showed significantly enhanced HFS-LTD compared with untreated YAC128(53) iSPNs [Fig. $7 D, E$; $t_{(14)}=4.109,{ }^{* *} p=0.0011, t$ test, JZL184 treated YAC128 $n=7(7)]$. Consistent with this result, the PPR of untreated YAC128 iSPNs was not significantly different after HFS (Fig. 7F; $t_{(8)}=0.0916$, $p=0.9293$, paired $t$ test), whereas YAC128 iSPNs treated with JZL184 showed an increase in PPR after HFS (Fig. $7 F ; t_{(6)}=$ $2.746,{ }^{\star} p=0.0334$, paired $t$ test), suggesting reduced probability of glutamate release at YAC128 corticostriatal synapses following HFS in the presence of JZL184. These results showed that the LTD deficit in YAC128 iSPNs can be rescued by enhancing endocannabinoid 2-AG signaling.

\section{Discussion}

In the present study we have shown a deficit in endocannabinoid-mediated highfrequency-induced LTD at corticostriatal (C-S) synapses in the YAC128 mouse model of Huntington's disease, an impairment rescued by augmenting 2-AG levels. Strikingly, YAC128 SPNs showed no change in endocannabinoid-dependent DSE, mGluR1/5 activation, or constitutive or agonist-induced CB1 activity. Moreover, mGluR2/3-dependent moderate frequency-induced LTD induced at thalamostriatal synapses (that do not express CB1) and C-S synapses is also preserved in YAC128 striatal SPNs.

Mutant $\mathrm{Htt}$ expression is associated with a decrease in CB1 in the striatum in many HD models. There is a decrease in the $\mathrm{CB} 1 \mathrm{mRNA}$ in the striatum of R6/2 Huntington mice starting at 4 weeks (Bisogno et al., 2008). In vivo PET scans show a decrease in CB1 in the caudate-putamen of early human HD and in a rat model of HD (Ooms et al., 2014). However, this decrease in receptor expression in the striatum as a whole does not address the possibility of a decrease at C-S synapses specifically. In fact, the level of CB1 protein expression in the cortical cell bodies that project to the striatum is unchanged in $\mathrm{R} 6 / 2$ mice, whereas $\mathrm{CB} 1$ protein is downregulated in indirect pathway SPNs and a subpopulation of interneurons (Glass et al., 2000; Horne et al., 2013). Consistent with those studies, we found that $\mathrm{CB} 1$ expression at excitatory terminals in the striatum of YAC128 mice is also unchanged as tested by colocalization with glutamate vesicle marker VGluT1, similar to a previous study in R6/2 mice (Chiarlone et al., 2014). The same study found no change in glutamate release from synaptosomes in response to $\mathrm{CB} 1$ activation. Another study also showed a selective loss of $\mathrm{CB} 1$ protein expression and inhibition of transmitter release at GABAergic synapses in R6/2, but no change at glutamatergic synapses (Chiodi et al., 
2012). The lack of change in CB1 at cortical-striatal synapses in the R6/2 model, and our own data showing normal levels of CB1 colocalization with VGluT1 in YAC128 striatum, suggest that the deficit in CB1 signaling at these synapses in YAC128 is not due to a reduced number of receptors.

Because cAMP signaling is impaired progressively in pre-manifest HD mouse striatum (Gines et al., 2003), it is possible that this pathway is impaired downstream of CB1 activation, and could explain a deficit in anandamide-mediated, CB1dependent synaptic plasticity. Presynaptic mGluR share a common downstream signaling pathway with $\mathrm{CB} 1$, involving cyclicAMP-dependent protein kinase $\mathrm{A}$ and the inhibition of $\mathrm{P} / \mathrm{Q}$-type $\mathrm{Ca}^{2+}$ channels to reduce glutamate release in the striatum (Robbe et al., 2002). A recent study found that LTD could be induced at both corticostriatal and thalamostriatal synapses by activating presynaptic mGluR2/3 (Johnson et al., 2017). Because thalamic projections to the striatum do not express CB1 (Uchigashima et al., 2007; Wu et al., 2015), moderate frequency-induced LTD is most likely mediated by presynaptic mGluR consistent with a previous study at C-S synapses (Kreitzer and Malenka, 2005), as we confirmed by blocking this form of LTD with a Group II mGluR inhibitor. The preservation of moderate frequency LTD in YAC128 striatum suggests that the deficit in HFS-LTD is not due to the impairment of signaling downstream of CB1 activation to inhibit presynaptic adenylyl cyclase. In addition, CB1-mediated LTD induced by stimulation of postsynaptic mGluR1/5 with the agonist DHPG was also intact in YAC128.

Previous studies show that DSE is mediated by calciumdependent production of 2-AG (Kreitzer and Regehr, 2001; Ohno-Shosaku et al., 2005; Shonesy et al., 2013). Consistent with this, we found that inhibition of CB1 receptors eliminated DSE in striatal SPNs, and that boosting 2-AG levels by inhibiting its degradative enzyme indeed enhanced DSE in our preparation. The fact that DSE is intact at C-S synapses in YAC128 striatum suggests normal 2-AG synthesis and release from striatal SPNs, and preserved 2-AG signaling via CB1 receptors on cortical terminals. Moreover, our data showing only a small, genotype-independent effect of the CB1 antagonist AM251 on basal SPNs synaptic activity and glutamate release probability from cortical terminals indicates that basal levels of CB1 activation are low and do not play a role in the differential response of WT and YAC128 SPNs to HFS (i.e., do not occlude this form of LTD).

In contrast to the role for 2-AG in DSE and DHPG- LTD at C-S synapses, previous studies indicate a dominant role for anandamide in mediating CB1-dependent HFS-LTD in the dorsal striatum (Ade and Lovinger, 2007; Lerner and Kreitzer, 2012). However, elevating levels of anandamide by blocking FAAH in YAC128 did not restore HFS-LTD in YAC128 striatal SPNs, suggesting that either anandamide synthesis is severely deficient or
B
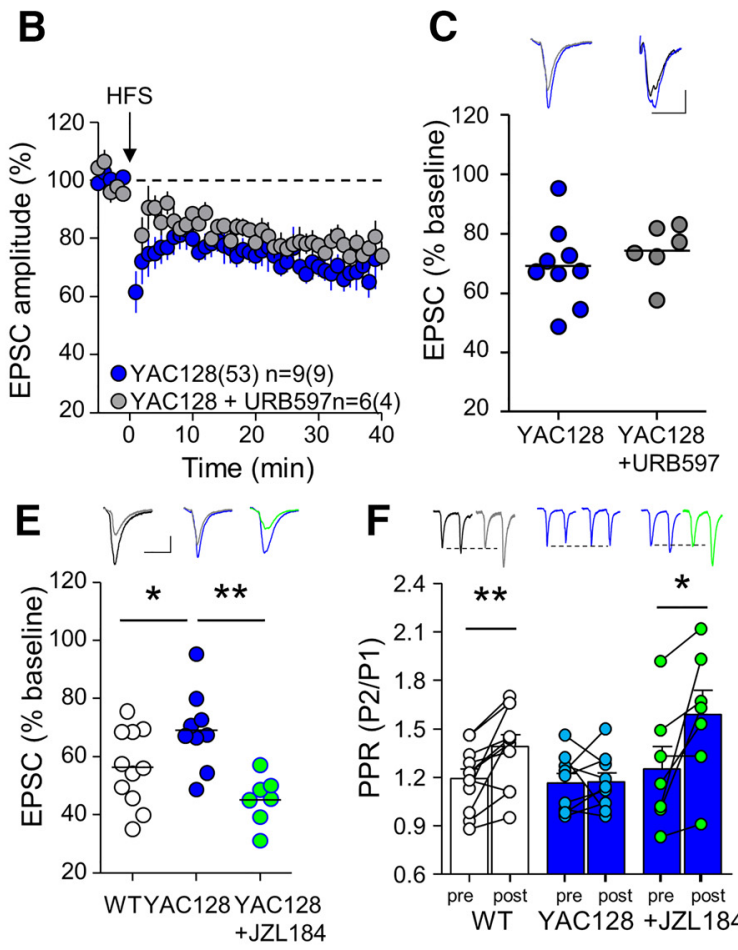

Figure 7. HFS-induced long-term depression rescued in YAC128 by increasing 2-AG levels. $\boldsymbol{A}$, Time course summary of normalized EPSC mplitude after HFS at time 0 in 1 month-old WT and YAC128(53) in indirect pathway SPNs (iSPNs). The same group of untreated 作 urse summary in A for WT and untreated YAC128, and from D for YAC128 treated with JZL 184) illustrate significantly greater reduction in shown in inset: pre-and post-HFS in WT, YAC128, and YAC128 treated with JZL184. Scale: 100 pA, 20 ms. F, Paired-pulse ratio (PPR) of EPSC after HFS is increased in WT iSPNs and YAC128 treated with JZL184, but not untreated YAC 128 iSPNs.

its activation of CB1 is substantially different to that of 2-AG. Biochemical and cell culture studies reveal that some CB1 agonists are functionally biased toward particular downstream pathways (Mallipeddi et al., 2017). We examined ability of two agonists of CB1, WIN55,212-2, and CP55,940 to inhibit glutamate release in the striatum and found no difference between genotypes, suggesting that YAC128 do not show an impairment in the CB1 response to particular agonists.

The synthesis of anandamide may be selectively impaired in YAC128. HFS-LTD in the striatum is dependent on mGluR5 as well as depolarization-induced stimulation of L-type calcium channels (L-VGCC) on striatal SPNs, which in turn triggers $\mathrm{Ca}^{2+}$-induced calcium release by ryanodine receptors (RyR) from ER stores, to increase synthesis of anandamide (Lerner and Kreitzer, 2012). One calcium-dependent enzyme involved in anandamide production after HFS is $N$-acyl-phosphatidylethanolamine-hydrolyzing phospholipase D (NAPE-PLD; Lerner and Kreitzer, 2012). We found postsynaptic mGluR activation by the agonist DHPG and DSE to be intact in YAC128 SPN. However, previous studies suggest that both $\mathrm{L}-$ VGCC and RyR-mediated $\mathrm{Ca}^{2+}$-induced $\mathrm{Ca}^{2+}$ release are altered early in HD (Suzuki et al., 2012; Braubach et al., 2014). A recent study also found that the anandamide synthetic enzyme NAPE-PLD is reduced in the striatum of the R6/2 model of HD (Bari et al., 2013). Future studies will determine whether L-VGCC and internal calcium stores are altered in striatal SPN in YAC128 and whether they can be modulated to restore LTD. 
In the hippocampus loss of $\mathrm{CB} 1$ at glutamatergic synapses leads to a greater loss of eCB stimulation of GTP $\gamma \mathrm{S}$ binding compared with removal of CB1 from GABAergic synapses, and this effect is stronger for 2-AG than anandamide (Steindel et al., 2013). The constitutive activity of CB1 is also greater at GABAergic synapses and minimal at glutamatergic synapses (Slanina and Schweitzer, 2005; Roberto et al., 2010), which could explain the modest effect of AM251 on spontaneous excitatory synaptic activity recorded from striatal SPNs in both WT and YAC128 slices. In the striatum there is more CB1 expressed at GABAergic synapses compared with glutamatergic synapses. However, CB1 at $\mathrm{C}-\mathrm{S}$ synapses play a key role in $\mathrm{HD}$. Deletion of CB1 selectively at corticostriatal synapses leads to an exacerbated HD phenotype in R6/2 mice and increased sensitivity to quinolinic acid in WT mice (Chiarlone et al., 2014).

The reduced ability to attenuate glutamate release onto YAC128 striatal SPNs by endocannabinoid-dependent CB1 signaling, as shown here by the LTD deficit in response to HFS of glutamatergic afferents, was most prominent in D2-expressing, iSPNs. In this regard, it is interesting that a recent report showed habit learning to be mediated by synaptic plasticity in iSPNs; in that study, training mice to lever-press for food pellets induced a depression of glutamatergic synaptic responses in iSPNs, but no change in dSPNs (Shan et al., 2015). In HD, iSPNs are the most vulnerable cell type and degenerate many years before diagnosis (Reiner et al., 1988; Plotkin and Surmeier, 2015). In WT rodents iSPNs also show higher levels of intrinsic excitability, as well as higher presynaptic glutamate release probability and larger NMDA receptor-mediated currents, than dSPNs (Kreitzer and Malenka, 2007; Cepeda et al., 2008). Together, these results suggest that impairment of HFS-LTD at cortico-iSPNs synapses in YAC128 striatum contributes to early deficits in motor learning (Milnerwood et al., 2010; Pouladi et al., 2013) as well as enhanced vulnerability of iSPNs to degeneration in HD patients and mouse models.

Motor learning deficits in HD may be further compounded by several striatal plasticity deficits. R6/2 mice show less NMDARdependent long-term potentiation (LTP) in the striatum compared with WT controls (Kung et al., 2007). Impairments in BDNF signaling also reduce LTP selectively in iSPN of BACHD and Q175 HD mice (Plotkin et al., 2014). With deficits in both LTD and LTP, $\mathrm{C}-\mathrm{S}$ synapses in $\mathrm{HD}$ would be more severely restricted and unable to respond to changing conditions. Compared with other brain areas, LTP in the striatum is difficult to study without pharmacological manipulation of NMDA and dopamine receptors (Shen et al., 2008, Lovinger, 2010). However, future studies are needed to determine the early conditions that result in a loss of bidirectional plasticity at C-S synapses in HD.

Elevating levels of 2-AG by blocking MAGL successfully rescued HFS-LTD in YAC128, which suggests that intact 2-AG signaling at $\mathrm{CB} 1$ can be engaged to compensate for deficits in endocannabinoid signaling in HD. CB1 is the most abundant G-protein-coupled receptor in the brain and direct agonists can have limited usefulness in the clinical setting because of their side effects (Schrot and Hubbard, 2016). Therapeutic strategies that enhance eCB signaling at the time of their release have better potential to maintain physiological function in brain networks. Targeting deficits in endocannabinoid-mediated synaptic plasticity at C-S synapses may improve motor learning. Moreover, SPNs are exquisitely vulnerable to degeneration in HD, due in part to extrasynaptic NMDAR signaling associated with cell death (Milnerwood et al., 2010), and enhanced eCB signaling could protect striatal SPNs from excessive glutamate stimulation.

\section{References}

Ade KK, Lovinger DM (2007) Anandamide regulates postnatal development of long-term synaptic plasticity in the rat dorsolateral striatum. J Neurosci 27:2403-2409. CrossRef Medline

André VM, Cepeda C, Fisher YE, Huynh M, Bardakjian N, Singh S, Yang XW, Levine MS (2011a) Differential electrophysiological changes in striatal output neurons in Huntington's disease. J Neurosci 31:1170-1182. CrossRef Medline

André VM, Fisher YE, Levine MS (2011b) Altered balance of activity in the striatal direct and indirect pathways in mouse models of Huntington's disease. Front Syst Neurosci 5:46. CrossRef Medline

Bari M, Battista N, Valenza M, Mastrangelo N, Malaponti M, Catanzaro G, Centonze D, Finazzi-Agrò A, Cattaneo E, Maccarrone M (2013) In vitro and in vivo models of Huntington's disease show alterations in the endocannabinoid system. FEBS J 280:3376-3388. CrossRef Medline

Bisogno T, Martire A, Petrosino S, Popoli P, Di Marzo V (2008) Symptomrelated changes of endocannabinoid and palmitoylethanolamide levels in brain areas of R6/2 mice, a transgenic model of Huntington's disease. Neurochem Int 52:307-313. CrossRef Medline

Blázquez C, Chiarlone A, Sagredo O, Aguado T, Pazos MR, Resel E, Palazuelos J, Julien B, Salazar M, Börner C, Benito C, Carrasco C, Diez-Zaera M, Paoletti P, Díaz-Hernández M, Ruiz C, Sendtner M, Lucas JJ, de Yébenes JG, Marsicano G, et al. (2011) Loss of striatal type 1 cannabinoid receptors is a key pathogenic factor in Huntington's disease. Brain 134:119136. CrossRef Medline

Bodor AL, Katona I, Nyíri G, Mackie K, Ledent C, Hájos N, Freund TF (2005) Endocannabinoid signaling in rat somatosensory cortex: laminar differences and involvement of specific interneuron types. J Neurosci 25:6845-6856. CrossRef Medline

Braubach P, Orynbayev M, Andronache Z, Hering T, Landwehrmeyer GB, Lindenberg KS, Melzer W (2014) Altered $\mathrm{Ca}(2+)$ signaling in skeletal muscle fibers of the R6/2 mouse, a model of Huntington's disease. J Gen Physiol 144:393-413. CrossRef Medline

Cepeda C, André VM, Yamazaki I, Wu N, Kleiman-Weiner M, Levine MS (2008) Differential electrophysiological properties of dopamine D1 and D2 receptor-containing striatal medium-sized spiny neurons. Eur J Neurosci 27:671-682. CrossRef Medline

Chiarlone A,Bellocchio L, Blázquez C, Resel E, Soria-Gómez E, Cannich A, Ferrero JJ, Sagredo O, Benito C, Romero J, Sánchez-Prieto J, Lutz B, Fernández-Ruiz J, Galve-Roperh I, Guzmán M (2014) A restricted population of CB1 cannabinoid receptors with neuroprotective activity. Proc Natl Acad Sci U S A 111:8257-8262. CrossRef Medline

Chiodi V, Uchigashima M, Beggiato S, Ferrante A, Armida M, Martire A, Potenza RL, Ferraro L, Tanganelli S, Watanabe M, Domenici MR, Popoli P (2012) Unbalance of CB1 receptors expressed in GABAergic and glutamatergic neurons in a transgenic mouse model of Huntington's disease. Neurobiol Dis 45:983-991. CrossRef Medline

Dau A, Gladding CM, Sepers MD, Raymond LA (2014) Chronic blockade of extrasynaptic NMDA receptors ameliorates synaptic dysfunction and pro-death signaling in Huntington disease transgenic mice. Neurobiol Dis 62:533-542. CrossRef Medline

Dowie MJ, Bradshaw HB, Howard ML, Nicholson LF, Faull RL, Hannan AJ, Glass M (2009) Altered CB1 receptor and endocannabinoid levels precede motor symptom onset in a transgenic mouse model of Huntington's disease. Neuroscience 163:456-465. CrossRef Medline

Gerdeman GL, Ronesi J, Lovinger DM (2002) Postsynaptic endocannabinoid release is critical to long-term depression in the striatum. Nat Neurosci 5:446-451. CrossRef Medline

Gines S, Seong IS, Fossale E, Ivanova E, Trettel F, Gusella JF, Wheeler VC, Persichetti F, MacDonald ME (2003) Specific progressive cAMP reduction implicates energy deficit in presymptomatic Huntington's disease knock-in mice. Hum Mol Genet 12:497-508. CrossRef Medline

Gladding CM, Fan J, Zhang LY, Wang L, Xu J, Li EH, Lombroso PJ, Raymond LA (2014) Alterations in STriatal-enriched protein tyrosine phosphatase expression, activation, and downstream signaling in early and late stages of the YAC128 Huntington's disease mouse model. J Neurochem 130:145-159. CrossRef Medline

Glass M, Dragunow M, Faull RL (2000) The pattern of neurodegeneration in Huntington's disease: a comparative study of cannabinoid, dopamine, adenosine and $\mathrm{GABA}(\mathrm{A})$ receptor alterations in the human basal ganglia in Huntington's disease. Neuroscience 97:505-519. CrossRef Medline

Graham RK, Pouladi MA, Joshi P, Lu G, Deng Y, Wu NP, Figueroa BE, 
Metzler M, André VM, Sl (2009) Differential susceptibility to excitotoxic stress in YAC128 mouse models of Huntington disease between initiation and progression of disease. J Neurosci 29:2193-2204. CrossRef Medline

Hardingham GE, Bading H (2010) Synaptic versus extrasynaptic NMDA receptor signalling: implications for neurodegenerative disorders. Nat Rev Neurosci 11:682-696. CrossRef Medline

Heintz N (2004) Gene expression nervous system atlas (GENSAT). Nat Neurosci 7:483. CrossRef Medline

Horne EA, Coy J, Swinney K, Fung S, Cherry AE, Marrs WR, Naydenov AV, Lin YH, Sun X, Keene CD, Grouzmann E, Muchowski P, Bates GP, Mackie K, Stella N (2013) Downregulation of cannabinoid receptor 1 from neuropeptide $\mathrm{Y}$ interneurons in the basal ganglia of patients with Huntington's disease and mouse models. Eur J Neurosci 37:429-440. CrossRef Medline

Johnson KA, Mateo Y, Lovinger DM (2017) Metabotropic glutamate receptor 2 inhibits thalamically-driven glutamate and dopamine release in the dorsal striatum. Neuropharmacology 117:114-123. CrossRef Medline

Kolodziejczyk K, Raymond LA (2016) Differential changes in thalamic and cortical excitatory synapses onto striatal spiny projection neurons in a Huntington disease mouse model. Neurobiol Dis 86:62-74. CrossRef Medline

Kreitzer AC, Malenka RC (2005) Dopamine modulation of state-dependent endocannabinoid release and long-term depression in the striatum. J Neurosci 25:10537-10545. CrossRef Medline

Kreitzer AC, Malenka RC (2007) Endocannabinoid-mediated rescue of striatal LTD and motor deficits in Parkinson's disease models. Nature 445: 643-647. CrossRef Medline

Kreitzer AC, Regehr WG (2001) Retrograde inhibition of presynaptic calcium influx by endogenous cannabinoids at excitatory synapses onto Purkinje cells. Neuron 29:717-727. CrossRef Medline

Kung VW, Hassam R, Morton AJ, Jones S (2007) Dopamine-dependent long term potentiation in the dorsal striatum is reduced in the R6/2 mouse model of Huntington's disease. Neuroscience 146:1571-1580. CrossRef Medline

Lerner TN, Kreitzer AC (2012) RGS4 is required for dopaminergic control of striatal LTD and susceptibility to parkinsonian motor deficits. Neuron 73:347-359. CrossRef Medline

Lovinger DM (2010) Neurotransmitter roles in synaptic modulation, plasticity and learning in the dorsal striatum. Neuropharmacology 58:951961. CrossRef Medline

Mallipeddi S, Janero DR, Zvonok N, Makriyannis A (2017) Functional selectivity at G-protein coupled receptors: advancing cannabinoid receptors as drug targets. Biochem Pharmacol 128:1-11. CrossRef Medline

Mievis S, Blum D, Ledent C (2011) Worsening of Huntington disease phenotype in CB1 receptor knockout mice. Neurobiol Dis 42:524-529. CrossRef Medline

Milnerwood AJ, Gladding CM, Pouladi MA, Kaufman AM, Hines RM, Boyd JD, Ko RW, Vasuta OC, Graham RK, Hayden MR, Murphy TH, Raymond LA (2010) Early increase in extrasynaptic NMDA receptor signaling and expression contributes to phenotype onset in Huntington's disease mice. Neuron 65:178-190. CrossRef Medline

Ohno-Shosaku T, Hashimotodani Y, Maejima T, Kano M (2005) Calcium signaling and synaptic modulation: regulation of endocannabinoid-mediated synaptic modulation by calcium. Cell Calcium 38:369-374. CrossRef Medline

Ooms M, Rietjens R, Rangarajan JR, Vunckx K, Valdeolivas S, Maes F, Himmelreich U, Fernandez-Ruiz J, Bormans G, Van Laere K, Casteels C (2014) Early decrease of type 1 cannabinoid receptor binding and phosphodiesterase 10A activity in vivo in R6/2 Huntington mice. Neurobiol Aging 35:2858-2869. CrossRef Medline

Parievsky A, Moore C, Kamdjou T, Cepeda C, Meshul CK, Levine MS (2017) Differential electrophysiological and morphological alterations of thalamostriatal and corticostriatal projections in the R6/2 mouse model of Huntington's disease. Neurobiol Dis 108:29-44. CrossRef Medline

Plotkin JL, Day M, Peterson JD, Xie Z, Kress GJ, Rafalovich I, Kondapalli J, Gertler TS, Flajolet M, Greengard P, Stavarache M, Kaplitt MG, Rosinski J, Chan CS, Surmeier D (2014) Impaired TrkB receptor signaling underlies corticostriatal dysfunction in Huntington's disease. Neuron 83:178188. CrossRef Medline

Plotkin JL, Surmeier DJ (2015) Corticostriatal synaptic adaptations in Huntington's disease. Curr Opin Neurobiol 33:53-62. CrossRef Medline
Pouladi MA, Morton AJ, Hayden MR (2013) Choosing an animal model for the study of Huntington's disease. Nat Rev Neurosci 14:708-721. CrossRef Medline

Reiner A, Albin RL, Anderson KD, D'Amato CJ, Penney JB, Young AB (1988) Differential loss of striatal projection neurons in Huntington disease. Proc Natl Acad Sci U S A 85:5733-5737. CrossRef Medline

Robbe D, Alonso G, Chaumont S, Bockaert J, Manzoni OJ (2002) Role of $\mathrm{P} / \mathrm{Q}-\mathrm{Ca}^{2+}$ channels in metabotropic glutamate receptor $2 / 3$-dependent presynaptic long-term depression at nucleus accumbens synapses. J Neurosci 22:4346-4356. Medline

Roberto M, Cruz M, Bajo M, Siggins GR, Parsons LH, Schweitzer P (2010) The endocannabinoid system tonically regulates inhibitory transmission and depresses the effect of ethanol in central amygdala. Neuropsychopharmacology 35:1962-1972. CrossRef Medline

Ronesi J, Gerdeman GL, Lovinger DM (2004) Disruption of endocannabinoid release and striatal long-term depression by postsynaptic blockade of endocannabinoid membrane transport. J Neurosci 24:1673-1679. CrossRef Medline

Schrot RJ, Hubbard JR (2016) Cannabinoids: medical implications. Ann Med 48:128-141. CrossRef Medline

Shan Q, Christie MJ, Balleine BW (2015) Plasticity in striatopallidal projection neurons mediates the acquisition of habitual actions. Eur J Neurosci 42:2097-2104. CrossRef Medline

Sheinin A, Talani G, Davis MI, Lovinger DM (2008) Endocannabinoid-and mGluR5-dependent short-term synaptic depression in an isolated neuron/ bouton preparation from the hippocampal CA1 region. J Neurophysiol 100: 1041-1052. CrossRef Medline

Shen W, Flajolet M, Greengard P, Surmeier DJ (2008) Dichotomous dopaminergic control of striatal synaptic plasticity. Science 321:848-851. CrossRef Medline

Shonesy BC, Wang X, Rose KL, Ramikie TS, Cavener VS, Rentz T, Baucum AJ 2nd, Jalan-Sakrikar N, Mackie K, Winder DG, Patel S, Colbran RJ (2013) CaMKII regulates diacylglycerol lipase- $\alpha$ and striatal endocannabinoid signaling. Nat Neurosci 16:456-463. CrossRef Medline

Slanina KA, Schweitzer P (2005) Inhibition of cyclooxygenase-2 elicits a CB1-mediated decrease of excitatory transmission in rat CA1 hippocampus. Neuropharmacology 49:653-659. CrossRef Medline

Slow EJ, van Raamsdonk J, Rogers D, Coleman SH, Graham RK, Deng Y, Oh R, Bissada N, Hossain SM, Yang YZ, Li XJ, Simpson EM, Gutekunst CA, Leavitt BR, Hayden MR (2003) Selective striatal neuronal loss in a YAC128 mouse model of Huntington disease. Hum Mol Genet 12:15551567. CrossRef Medline

Southwell AL, Smith-Dijak A, Kay C, Sepers M, Villanueva EB, Parsons MP, Xie Y, Anderson L, Felczak B, Waltl S, Ko S, Cheung D, Dal Cengio L, Slama R, Petoukhov E, Raymond LA, Hayden MR (2016) An enhanced Q175 knock-in mouse model of Huntington disease with higher mutant huntingtin levels and accelerated disease phenotypes. Hum Mol Genet 25:3654-3675. CrossRef Medline

Steindel F, Lerner R, Häring M, Ruehle S, Marsicano G, Lutz B, Monory K (2013) Neuron-type specific cannabinoid-mediated G protein signalling in mouse hippocampus. J Neurochem 124:795-807. CrossRef Medline

Suzuki M, Nagai Y, Wada K, Koike T (2012) Calcium leak through ryanodine receptor is involved in neuronal death induced by mutant huntingtin. Biochem Biophys Res Commun 429:18-23. CrossRef Medline

Tanimura A, Yamazaki M, Hashimotodani Y, Uchigashima M, Kawata S, Abe M, Kita Y, Hashimoto K, Shimizu T, Watanabe M, Sakimura K, Kano M (2010) The endocannabinoid 2-arachidonoylglycerol produced by diacylglycerol lipase alpha mediates retrograde suppression of synaptic transmission. Neuron 65:320-327. CrossRef Medline

Uchigashima M, Narushima M, Fukaya M, Katona I, Kano M, Watanabe M (2007) Subcellular arrangement of molecules for 2-arachidonoyl-glycerolmediated retrograde signaling and its physiological contribution to synaptic modulation in the striatum. J Neurosci 27:3663-3676. CrossRef Medline

Wang Z,Kai L, Day M, Ronesi J, Yin HH, Ding J, Tkatch T, Lovinger DM, Surmeier DJ (2006) Dopaminergic control of corticostriatal long-term synaptic depression in medium spiny neurons is mediated by cholinergic interneurons. Neuron 50:443-452. CrossRef Medline

Wu YW, Kim JI, Tawfik VL, Lalchandani RR, Scherrer G, Ding JB (2015) Input- and cell-type-specific endocannabinoid-dependent LTD in the striatum. Cell Rep 10:75-87. CrossRef Medline 